\title{
Retraction statement: Safety and efficacy of tramadol in the treatment of idiopathic detrusor overactivity: A double-blind, placebo-controlled, randomized study
}

Retraction: Safarinejad, M. R. and Hosseini, S. Y. (2006), Safety and efficacy of tramadol in the treatment of idiopathic detrusor overactivity: a double-blind, placebo-controlled, randomized study. British Journal of Clinical Pharmacology, 61: 456-463

The above article, published online on $14^{\text {th }}$ February 2006 in Wiley Online Library (wileyonlinelibrary.com), has been retracted by agreement between the authors, the journal Editor in Chief, Prof. JM Ritter and John Wiley and Sons Ltd. The retraction has been agreed due to statistical errors which have come to light and which undermine confidence in the results presented.

\section{REFERENCE}

Safarinejad, M. R. and Hosseini, S. Y. (2006), Safety and efficacy of tramadol in the treatment of idiopathic detrusor overactivity: a double-blind, placebo-controlled, randomized study. British Journal of Clinical Pharmacology, 61: 456-463. doi:

10.1111/j.1365-2125.2006.02597.x 